\title{
A Multiagent Negotiation Based Model to Support the Collaborative Supply Chain Planning Process
}

\author{
Jorge E. Hernández ${ }^{1}$, Josefa Mula ${ }^{2}$, Raúl Poler ${ }^{2}$, Juan Pavón ${ }^{3}$ \\ 1 Dpto. Organización de Empresas, Universidad Politécnica de Valencia, \\ Edificio Ferrándiz y Carbonell, 2, \\ 03801 Alcoy (Alicante), Spain. \\ jorge.industrial@gmail.com. \\ 2 CIGIP (Centro de Investigación Gestión e Ingeniería de Producción), \\ Dpto. Organización de Empresas. Escuela Politécnica Superior de Alcoy, \\ Universidad Politécnica de Valencia, \\ Edificio Ferrándiz y Carbonell, 2, \\ 03801 Alcoy (Alicante), Spain. \\ fmula@cigip.upv.es, rpoler@cigip.upv.es. \\ 3 Facultad de Informática, Universidad Complutense de Madrid, \\ Ciudad Universitaria s/n, \\ 28040 Madrid, Spain. \\ jpavon@fdi.ucm.es.
}

\begin{abstract}
Multiagent systems are inherently distributed and support well the modelling of organizational issues such as negotiation mechanisms and workflows. In this sense, a decentralized supply chain configuration process can be easily modelled as an information sharing processes where nodes (agents) collaborate, for example, in planning and decision-making. This paper presents a novel collaborative planning model for supply chain networks that supports a distributed negotiation process from a decentralized perspective. The hypothesis presented herein is that by collaborating in the information exchange related with the visibility of the demand plans, improvements on the total profit level of the supply chain nodes, and of the supply chain as whole, can be found.
\end{abstract}

Keywords: Decentralized collaborative planning, supply chain management, multiagent system, negotiation.

\section{Introduction}

A supply chain can be defined as a group of parties or partners and also as a distribution network oriented to perform functions such as materials procurement, transformation of these materials into intermediate and finished products, and the distribution of these finished products to customers. From the final customers' point of view, all the demand needs to be satisfied at the right time and in the right quantity. The concept of supply chain management arises then to integrate all the processes oriented to manage (from the physical, organizational, decisional and technological points of view), how all the parties should be organized in order to satisfy this initial demand. From a modelling point of view, the supply chain can be modelled as a network of autonomous supply chain nodes [28], where the main node actions, such as orders, order filling, shipping, receiving, production, etc., and node policies, such as inputs and outputs, inventory policies, costs and rates, are also considered from a linked relationship establishing their links and common constrains.

In order to support this linked relationship it is important to consider and accept the goals of every node (at least, for most of them). Many of these goals are related to improvement processes, so the fact that supply chain nodes tend to generate innovation in their processes should be considered. Furthermore, nowadays most innovation and research works are done by partnerships of competent entities each having some specialized skills, which imply that innovation can be categorized into four types: derivative, platform, breakthrough and processes [29]. In this sense, when the innovation is supported by mutual agreements among the supply chain nodes, it is possible to talk about co-innovation. Thereafter, the co-innovation concept refers mainly to support external partnerships to exploit new technologies, knowledge, processes, etc. Nevertheless, under a coinnovation perspective, it is more difficult to apply the 'win-win' principle, because the 
likelihood of stopping before the product is marketed is significant [16]. Therefore, a positive response to this challenge would be a collaborative innovation in pursuit the continuous improvement on the existing processes and the development of products and services as well, which add value to the final consumer [8] and to the supply chain members. Hence, the collaborative processes will emerge by sharing the proper information in order to enhance the collaboration in supply chains, which is important in terms of innovation such as high quality, lower costs, more timely deliveries, efficient operations and the effective coordination of activities [25]. Thus, the level of collaboration in the supply chain will depend on whether the supply chain members are willing to share and exchange the information required to support their planning process [9]. Moreover, the supply chain management trend is to move from the classical centralised approach toward the decentralized information processes [13]. Within this it is possible to ensure an independent supply chain interaction which means that the right technology must be considered in order to support these complex facts. In this context, one of the best technologies in order to support this is the multiagent paradigm [14]. These technologies, among many perspectives, consider the decentralized and collaborative approaches in supply chains. Moreover, under a planning context, the supply chain planning plays a key role regarding to the required coordination effort among the nodes [22]. Thereafter, in order to give a solution proposal to this complex issue related to collaborative supply chain management matters, this paper presents a novel decentralized collaborative planning model for supply chain co-innovation by implementing a multiagent-based negotiation model (ANEM).

Therefore, the main contribution of this paper is twofold; firstly, the theoretical proposal of a decentralized collaborative supply chain production planning model in an MRP environment; secondly, the practical validation of this model by using a multiagent-based model in a specific problem. Current proposals in the literature address this problem in a more general way by mainly focusing on technological requirements and advances. The main advantage of this proposal is that it addresses very specifically, theoretically, practically and in detail the supply chain production planning problem in a collaborative manner and in a decentralized MRP environment.

This paper is set out as follows: Section 2 reviews the relevant literature on multiagent systems in the supply chain management under a collaborative planning context. Section 3 extends the collaboration concept to the decentralized perspective in the supply chain. Then, Section 4 provides experimental results to validate the ANEM proposal and also highlights their contributions to the multiagent research field from a qualitative point of view. Finally, Section 5 provides the main conclusions and further research.

\section{Background}

The supply chain models are oriented to identify and establish the main elements of the system and their relationships, especially from the technological perspective. From this perspective, the agent paradigm has already been considered to model and simulate complex supply chain management processes by showing their robustness, as explained in some state-of-the-art reviews, such as [4] and [23]. In the context of supply chain management, one of the first modelling approaches is presented by [3], which proposes a client-broker-server architecture. Moreover, the agent used as a coordination mechanism presents a solid foundation for the development of cooperative applications in global manufacturing processes. In addition with a supply management approach, in their framework, [27] propose one of the first applications of the multiagent system for collaborative planning, forecasting and replenishment. Thus from the agent perspective, [27] considers the organization as a collection of roles, which contemplates the relationship among them in order to support the systematic interactions among the roles. Thus, by considering the robustness presented by the multiagent system, [18] propose to consider this technology with a view to supporting inter-enterprise functions and resources for integration and collaboration in a networked context. This is 
because agents are able to exhibit both hybrid behaviours and interactions. In this same supply chain planning context, [10] express that agents are a good tool to model specific behaviours and conversation protocols in which relationships are to be supported by each agent's local information on products, processes, and processors.

Thereafter, it is possible to establish that by considering a collaborative supply chain approach, distribution of the planning decisions among specialized planning agents, the agent-based platform could increase the supply chain's agility and performance. Hence the multiagent system-based platform supports production centres to independently react to the environmental changes and production plans by considering each agent's feasibility and coordination [11]. Moreover, and at the same time, agents interact through a complementary process to establish firm agreements (or contracts) based on the local schedules created by means of the auction process. These agreements determine fixed programs for the earliest scheduled tasks [2]. Furthermore, [26] establishes an agent model that is composed of three main layers: communication, coordination and cooperation. Thereafter, [5] proposes an architecture model in order to facilitate the organizational memory in supply chains. Two layers are considered: the storage layer and the facilitation layer, which represent the task and domain knowledge and harmony mechanisms by using the shared knowledge supported by agents, collaborators, transactors, objects and registry facilitators. In this context and from a structural point of view, the organization can be considered as a set of entities with relationships of aggregation and inheritance, agents, resources, goals, and tasks can be placed regarding to the intrinsic workflows and social rules from the environment [19].

Moreover by considering the recent and relevant contributions on collaboration in supply chains from [1], [14], [15] and [12], it is possible to establish that the collaboration among the supply chain nodes is given by the iterative interaction among them in order to achieve the desired goals. This, has been defined by [11], is due to the fact that agents and supply chains compose a number of independent units which collaborate in order to reach their own goals. In addition, as suggested by [11] a contract net based protocol need to be considered in order to implement the negotiation development process among the agent in the supply chain. In this same line important is to highlight the decoupled federated model presented by [7] in where distributed supply chains simulation cloning, fault tolerance and interoperability [13] are considered. Under this interoperability concept, the ontology issue to support the standard agent communication has been considered by [21], where a negotiation model is supported by three layers to give the flexibility to the negotiation ontology: the negotiation, the semantic and the knowledge management system layer.

In addition, it can be highlighted that with a collaborative planning approach there will be an information flow supported by the sharing of demand plans, capacity and inventory levels in order to reach the agent's own goals. Moreover, negotiation parameters will be considered, such as the supply chain's and each node's level of profit and the price changing process to promote the new offers among nodes. Thereafter, several conclusions can be drawn from the reviewed agent-based models: agents can facilitate the development of technological models to handle supply chain processes, they help to identify the main elements and their relationships, and they support the related innovation processes under a collaborative supply chain context. In the next section, we present the ANEM proposal for the supply chain collaborative planning process in a decentralized context. Finally, from a qualitative point of view, Subsection 4.3 presents the main ANEM contributions regarding the studied background.

\section{Decentralized Collaborative Supply Chain Planning Formulation}

The proposed planning process (see Figure 2) considers right and on-time information sharing to support the supply chain planning process from a decentralized collaboration perspective which is included in each ERP (enterprise resource planning) system in each node. Thus from a generic point of view, this 
identifies the main inputs and outputs linked to the related information flow in the supply chain planning processes. Therefore, the ANEM proposal contemplates a capacity constrained material requirement planning $(M R P)$ system, whose main information for all the $\mathrm{n}$ periods (i) implies inputs such as demand $(D)$, inventory level (INV), selling price $(S P)$ and capacity $(C A P)$. On the other hand, the main MRP outputs are the following: planned orders at level $n$ (POLn), delay on demand $(D o D)$, profit and $S P$. Hence independently, each node supports its own ERP system by considering its MRP inputs, outputs and constraints. Then, each node runs its own MRP mechanism. The collaborative perspective of this proposal, as seen in Figure 1, establishes the communication at the multilevel area of the supply chain by considering the customer node's POLn, which is contemplated as $D$ in the directly relating tier suppliers; and the $P O L n$ relating with the $C A P$ information that the customer owns. Thus, the main idea is to support a negotiation process by incrementing the $S P$ in a specific factor, inc, in order to assess each node's total level of profit. This will allow supply chain nodes to support their own decision-making processes and to assess when the negotiation process must continue or stop. In fact, if no agreement is reached among the nodes, the proposal will be improved by raising the $S P$. From a decentralized and collaborative perspective, each node in the multi-level collaborative planning process considers its own databases (or information repository) to link the communication process. This kind of communication is considered decentralized and collaborative because it supports the multidirectional informational flow, and information is stored in independent databases which allow the desired information to be shared, requested or answered with the nodes related in the ANEM proposal.
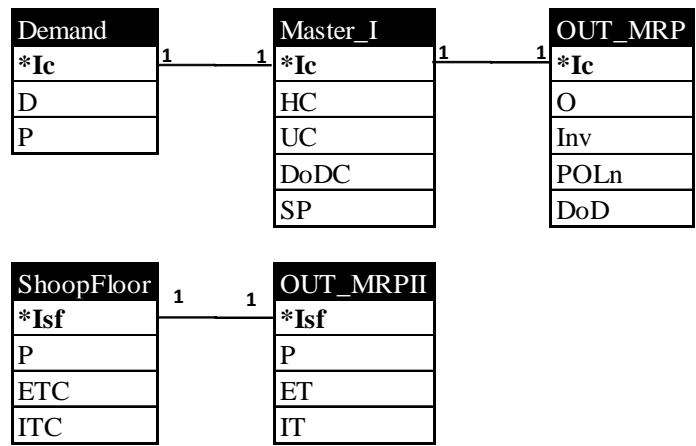

Figure 1. ANEM Class-based diagram to support decentralized collaborative planning.

Under the ANEM proposal the information system structure is composed of five main tables (Figure 1). These tables aim to collect the inputs and outputs generated by the MRP mechanism (extension from the work of [17]).

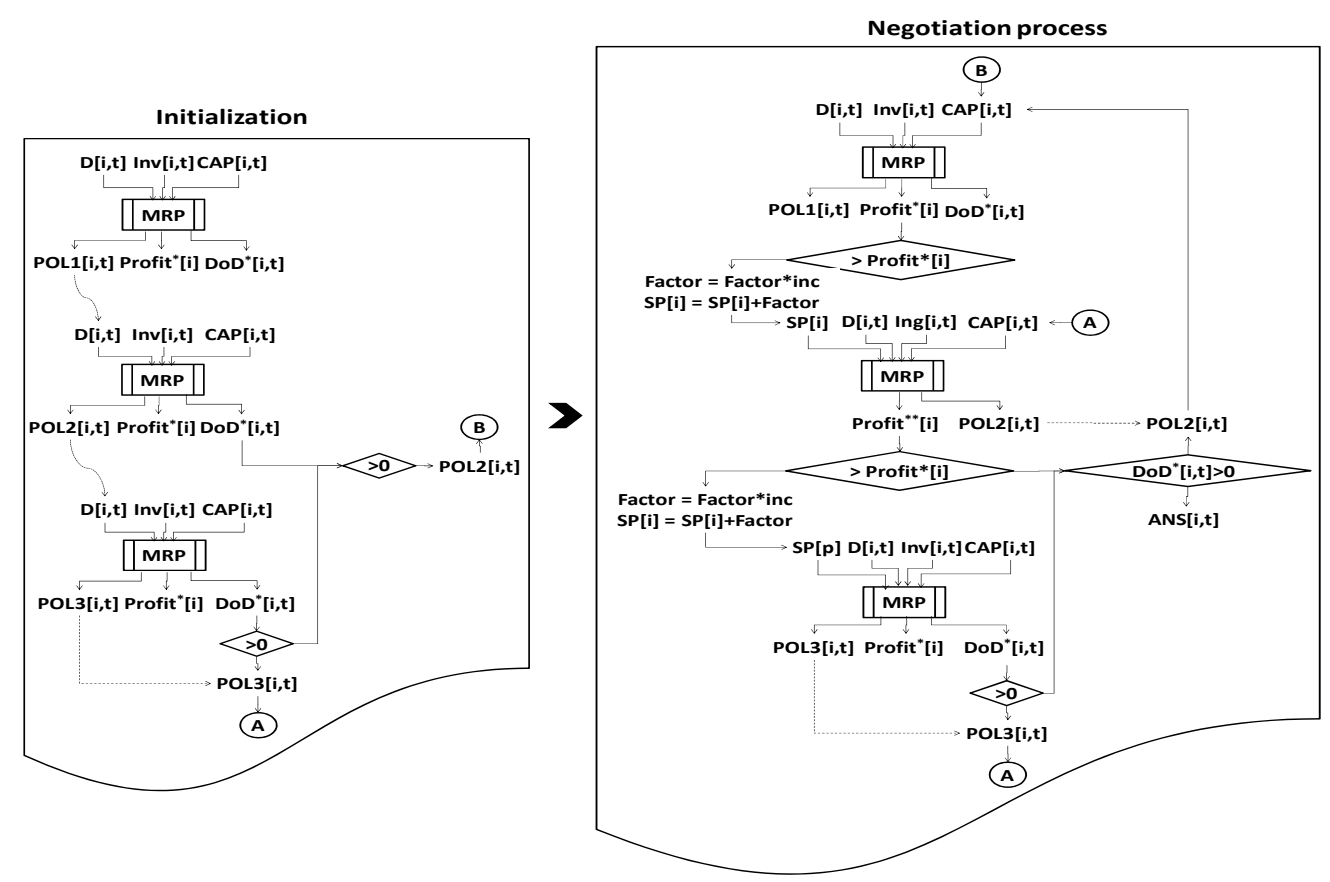

Figure 2. ANEM mechanism for decentralized collaborative supply chain planning. 
In this case, Figure 2 shows that the Demand table is about demand information. The Master_I table includes the information related to holding costs $(H C)$, unitary costs $(U C)$, delay on demand costs $(D o D C)$ and the sell price $(S P)$. The OUT_MRP table manages information on the final level of the inventory (INV), POLn and DoD. MRP systems also consider that information related to production activities, such as $C A P$, extra time cost (ETC) and idle time cost (ITC). Then, each answer (ANS) generated by the system will be restricted by the information in this table. Thus given the collaborative planning proposal, this information will consider the ANS from the tier supplier to assess the level of profit in the planning proposals. In this case, the ANS will be considered negative (which will imply a new iteration process) when $D o D[I, t]>0$, which will imply the generation of the next POLn. On the other hand, the ANS will be considered positive and the negotiation process will be stopped in order to evaluate the request within the ANS related to the higher levels. Then, according to the OUT_MRPII table, the supply chain will be able to evaluate its decision by considering the right and on-time information in an iterative decentralized negotiation process.

Hence, for each period, the following information is considered for the profit calculus: inventory costs at each period (1), production costs (2), delay on demands costs (3), extra time costs (4), costs of the idle time of resources (5) and sell revenues (6 and 7). Thus, by taking into account the ANS from suppliers (lower levels), the customer node (higher levels) evaluates renegotiation by taking the new profit value which is directly affected by the raised product's sell price and the related $D o D$. The negotiation process finishes when the changes on the new price changes have no longer an impact on the profit level or when no DoDC for the suppliers exists. An example of the application of this novel proposal to a multilevel supply chain is briefly provided in the following section. Finally, the total level of profit (8) leads not only to the negotiation process, but also to the decisions related to the planning process in each $n$ period of the planning horizon for each node and the supply chain as a whole.

$$
\begin{aligned}
& i c=\sum_{N=1}^{M} \sum_{i=1}^{n}\left(O U T \_M R P . I n v_{N i} * \text { Master_I.HC } C_{N i}\right) \\
& p c=\sum_{N=1}^{M} \sum_{i=1}^{n}\left(O U T_{-} \text {MRP.P.P } P_{N i} * \text { Master_I.UC } C_{N i}\right) \\
& d c=\sum_{i=1}^{n}\left(O U T_{-} M R P . D o D_{1 i} * \text { Master_I.DoDC } C_{N i}\right) \\
& \text { extratc }=\sum_{i=1}^{n}\left(\text { OUT_MRPII.ET } T_{N i} * \text { ShoopFloor.ETC } C_{1 i}\right) \\
& \text { idletc }=\sum_{N=1}^{M} \sum_{i=1}^{n}\left(O U \text { I_MRP.IT }_{N i} * \text { ShoopFloor.ITC } C_{N i}\right) \\
& s r 1=\sum_{i=1}^{n}\left(\text { Demand } . D_{1 i} * \text { Master_I.SP } P_{1 i}\right) \\
& s r 2=\sum_{i=1}^{n}\left(M R P . D o D_{1 i} * \text { Master_I.SP } 1 i\right) \\
& \text { PROFIT }=s r 1-s r 2-i c-p c-d c-e x t r a t c-i d l e t c
\end{aligned}
$$




\section{Multiagent Negotiation Model to Support Collaborative Planning}

\subsection{The multiagent-based supply chain structure}

In order to define the structure of the ANEM proposal, it is important to consider the perspective defined by [20], which establishes that the users of the system navigate through the taxonomy of communities and invoke the their target generic operations. Then, if an invoked operation requires some pre-operations to be executed before it, the system builds a process diagram for these pre-operations. The multiagent-based model ANEM, which supports the supply chain structure (Figure 3 ), facilitates the communication mechanism among the entities (or users), systems and models.Thus, the main goal of the ANEM proposal is to support the negotiation mechanisms in the decentralized collaborative planning structure among the supply chain tiers. Hence, the model considers the fact of the decentralization notion of the information flow. of CFP messages as well. The last one is oriented to receive the CFP request and answer the requests.

There are different types of messages which activate the agents' different behaviors and states (Figure 3): CFP (A), propose (B), reject (C) and accept (D). Thus each agent, depending on its supply chain level (customer, manufacturer or supplier), might consider the requesting, requesting-answering or just the answering behaviors. A full description of these agent types and their behaviors can be seen in [12]. In addition, it is possible to state from Figure 3 that there are common states for agents for each behavior. These are related to the requesting and answering process.

Then, the ANEM structure presents a novel combination among the decentralized perspectives by considering open-source databases structures (MySQL 5.0) in order to support the main information flow among the different nodes and CPLEX as an external $E R P$ (enterprise resource planning) system to carry out the decentralized planning process, which supports the profit calculus from Equation 8. Finally, the FIPA-ACL standard

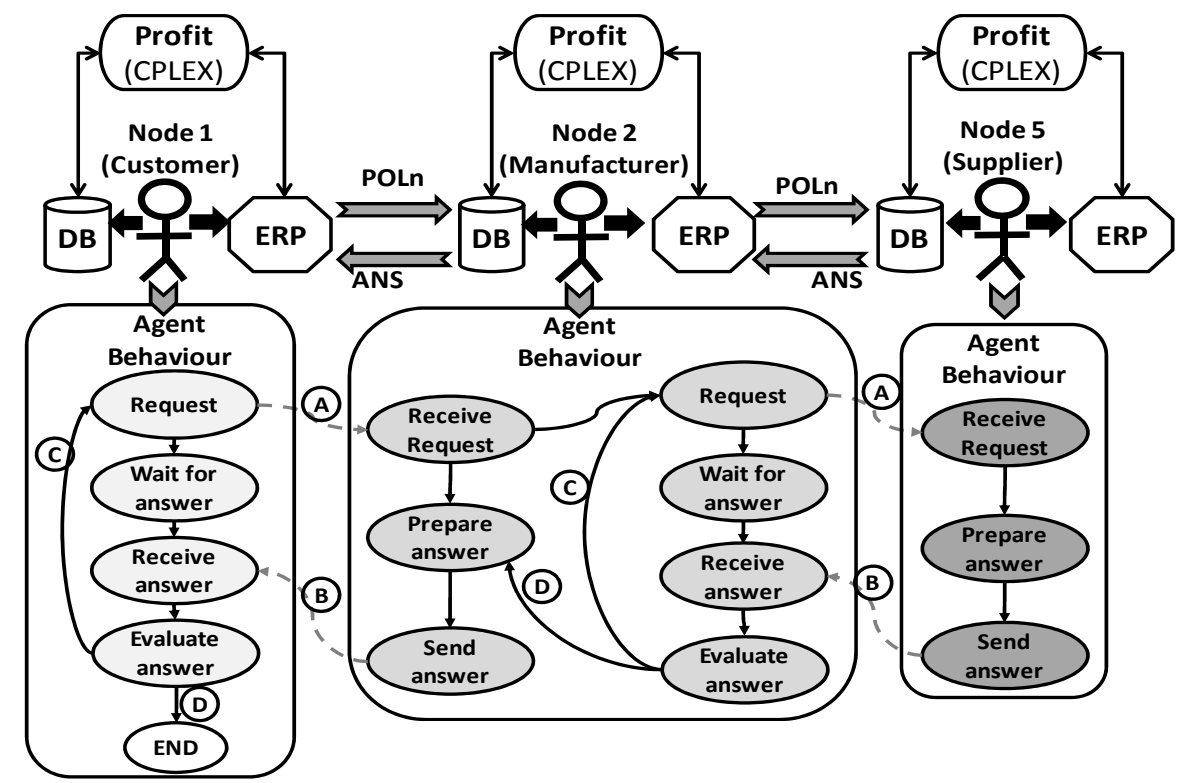

Figure 3. ANEM structure for the multi-level and decentralized collaborative supply chain.

As it can be seen in the Figure 3, three types of agent can be defined. The first one is related to an agent that generates a CFP (call for proposal) in order to offer proposals and receive answers. The second one corresponds to the reception of a CFP and the generation communication protocol is considered within the JADE 3.6 libraries. In this context, the ANEM proposal presents a novel way to also attempt FIPA-ACL CFP messages in a distributed fashion (Figure 4). 
ACLMessage msjCFP $=$ new ACLMessage $($ ACLMessage.CFP):

msjCFP.setProtocol(FIPANames.I nteractionProtocol.FIPA CONTRACT_NET);

msjCFP.setReplyByDate(new Date(System.currentTimeMillis() +

Constantes.timeoutRespuestas (N)):

try \{

addBehaviour(new CNI nitiatorCustomer(this, msjCFP) \{

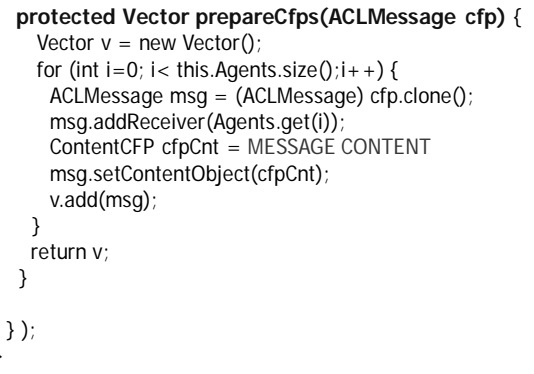

Figure 4. Distributed structure for the CFP supply chain messages.

This allows a distributed communication among the agents by considering the distributed thread behaviour which is validated in Figure 5, where it is possible to observe the main CFP process with its related sub-CFP process where the main CFP is paused until the sub-CFP finishes. information flow, related to every thread, behaves collaboratively regarding to the fact that the agents wait until receive an answer in order to keep going with the negotiation process.

The following section shows the validation of the proposal illustrated by a numerical example that is tested with three scenarios: the idealistic (S1), the non-collaborative (S2) and the collaborative (S3).

\subsection{Validation of the decentralized collaborative planning proposal}

It has been seen how a multiagent system can support the modelling process related to the supply chain management in order to improve key issues such as information flow, thread behaviours or even innovation in the supply chain by sharing the relevant information. In order to show the dynamical impact on the decision-making process related to the supply chain nodes, this section

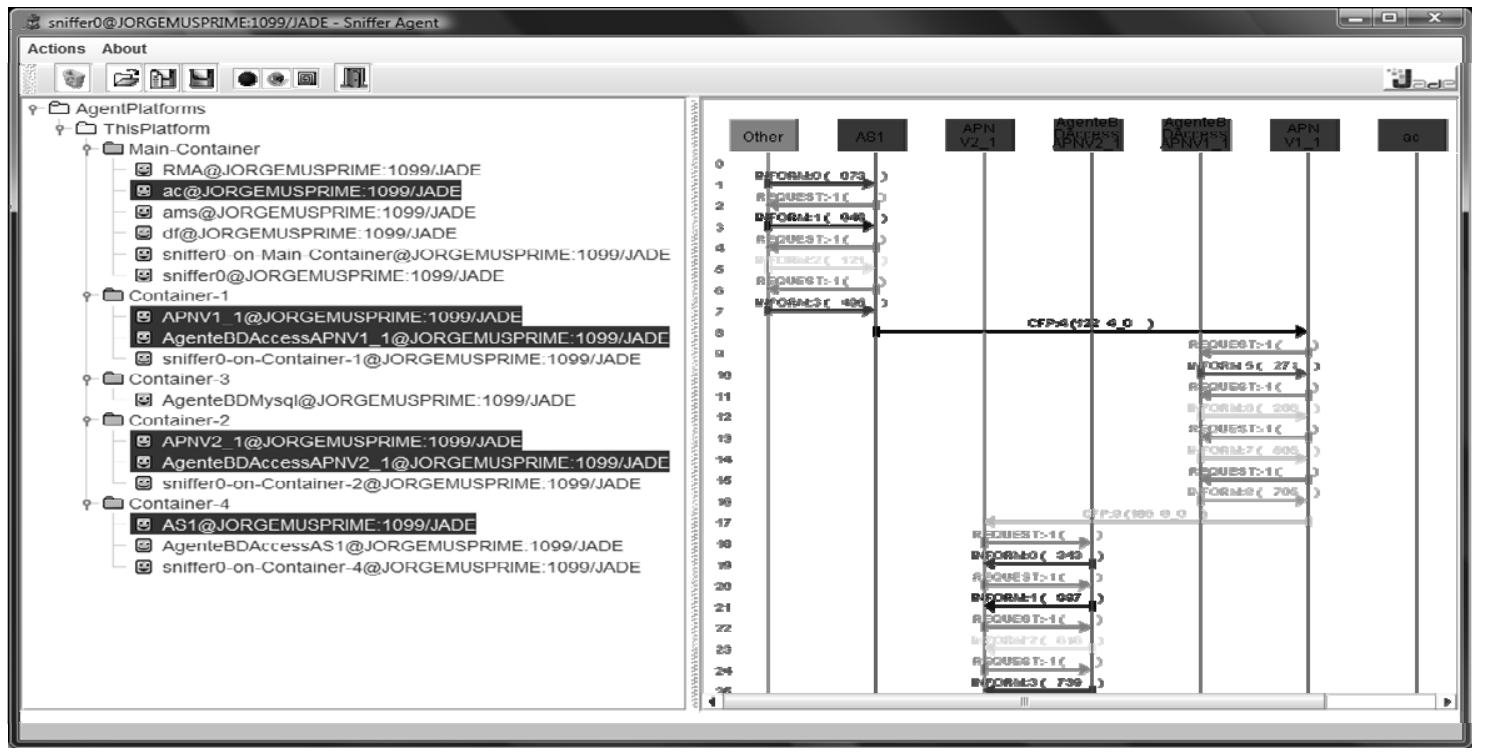

Figure 5. The distributed negotiation JADE agent-based negotiation process interface.

Hence, the decentralized structure of the supply chain is supported by a distributed negotiation process under the CFP FIPA$A C L$ messaging context. The critical issue regarding to this matter is the implementation. In this decentralized collaborative structure, the multi-behaviour and multithread are supported by decentralizing the core activities and allowing the agents to handle the messaging flow information. In addition, Figure 5 (CFP:4 and CFP:9, specifically) shows that the shows a numerical example in order to test this decentralized collaborative model from the implementation point of view. A linear supply chain of three levels has been considered, where each supply chain node is related to their own container, which is managed by the main container of the JADE platform. This main container is oriented to manage, as well, the generic behaviours of the multiagent system.

A realistic demand has been considered in order to evaluate the behaviour of the agent 
in every scenario (S1, S2 and S3). The realistic demand is based on the fact that many companies experiment some difficulties in order to cover their demand, hence the demand pattern and scenarios are linked in the following way:

- S1: It considers that no problem related to the demand plan and the available capacities will exist. Then, it is expected that every order will be served at the right time and in the right quantity.

- S2: It assumes the existence of node capacity problems regarding to the demand plans. In addition, nocollaboration is considered, thus problems in fulfilling the orders are awaited.

- S3: It considers node capacity problems regarding to the demand plans. Nevertheless, a collaborative approach is considered and solutions and fixed order are expected from the nodes.

The planning horizon considers 22 periods to collect and transmit the information among the nodes. Table 1 shows the results of the multiagent-based simulation with the numerical behaviour of the three proposed scenarios. Red and Blue squares highlight answer problems regarding to the customer demand and Green squares show the fixed orders supported by the collaborative scenario. right quantity as expected. Blue arrows show the requesting process, and green arrows represent the answering process.

Scenario S2 shows that the Node2 and Node5 (suppliers) are not able to answer at time to the requested order from Node1. This is due to the fact that capacity constraints are linked to these nodes.

Also, it is observed that, regarding to the noncollaborative approach, no selling prices (SP) are considered in S2, then there is no intention from the agent to solve the problematic order. Regarding to this, a lower profit level is expected as well.

From scenario S3, where a collaborative environment is considered, it is possible to see that initial demand problems remain, but there is an intention to solve this situation. This is supported by an incremental SP rate, which establishes the fact that if there is a problem with some supplier in order to fulfil the right order, the customer will try to offer some solution (monetary solutions in this case) to be considered by the supplier and evaluate and find out if the new proposal fit their own requirements. Then, S3 shows that fact that a final agreement comes out among customer and suppliers.

Additionally, the impact on the profit level is analyzed for every node and scenario. Figure 6

Table 1. MySQL-based trace for the three scenarios of collaboration in the supply chain.

\begin{tabular}{|c|c|c|c|c|c|c|c|c|c|c|c|c|c|c|c|c|c|c|c|c|c|c|c|c|c|c|c|c|}
\hline & I & ctor & SP & $\begin{array}{l}\text { Sender } 1 \\
\end{array}$ & Recei & 1 & P01 & P02 & P03 & P04 & $\begin{array}{l}\text { P05 } \\
\end{array}$ & P06 & $\begin{array}{l}\text { P07 } \\
\end{array}$ & P08 & $\begin{array}{l}\text { P09 } \\
\end{array}$ & P10 & P11 & P12 & P13 & P14 & P15 & P16 & P17 & P18 & P19 & P20 & P21 & P22 \\
\hline mand & & & & FC & Node1 & Request & 0 & 0 & $0 / 3$ & 300 & 0 & 0 & 0 & 0 & 0 & 0 & 0 & 1000 & 0 & 0 & 0 & 0 & 0 & 0 & 0 & 0 & 700 & 0 \\
\hline \multirow{4}{*}{ VI } & 1 & 1 & 36 & Node1 & Node2 & Request & 0 & & & 0 & 0 & 0 & 0 & 0 & 0 & & 000 & 0 & 0 & 0 & 0 & 0 & 0 & 0 & 0 & & 0 & 0 \\
\hline & 1,1 & 1 & 9 & Node2 & Node5 & Request & 0 & 300 & 0 & 0 & 0 & 0 & 0 & 0 & 0 & 100 & 0 & 0 & 0 & 0 & 0 & 0 & 0 & 0 & $700^{\circ}$ & 0 & 0 & 0 \\
\hline & 1,1 & 1 & 9 & Node5 & Node2 & Answer & 0 & 300 & 0 & 0 & 0 & 0 & 0 & 0 & 0 & 1000 & 0 & 0 & 0 & 0 & 0 & 0 & 0 & 0 & 700 & 0 & 0 & 0 \\
\hline & 1 & 1 & 36 & Node2 & Node1 & Answer & 0 & 0 & 300 & 0 & 0 & 0 & 0 & 0 & 0 & 0 & 1000 & 0 & 0 & 0 & 0 & 0 & 0 & 0 & 0 & 700 & 0 & 0 \\
\hline \multirow{4}{*}{ S2 } & 1 & 1 & 36 & Node1 & Node2 & Request & 0 & 0 & 300 & 0 & 0 & 0 & 0 & 164 & 230 & 336 & 270 & 0 & 0 & 0 & 0 & 0 & 0 & 0 & 273 & 427 & 0 & 0 \\
\hline & 1,1 & 1 & 9 & Node2 & Node5 & Request & 0[ & 270 & 30 & 0 & 0 & 0 & 164 & 230 & 336 & 270 & 0 & 0 & 0 & 0 & 0 & 0 & 127 & 327 & 246 & 0 & 0 & 0 \\
\hline & 1,1 & 1 & 9 & Node5 & Node2 & Answer & 0 & 226 & 74 & 0 & 0 & 0 & 164 & 230 & 336 & 270 & 0 & 0 & 0 & 0 & 0 & 0 & 127 & 327 & 246 & 0 & 0 & 0 \\
\hline & 1 & 1 & 36 & Node2 & Node1 & Answer & 0 & 0 & 270 & 30 & 0 & 0 & 0 & 164 & 230 & 336 & 270 & 0 & 0 & 0 & 0 & 0 & 0 & 0 & 273 & 427 & 0 & 0 \\
\hline & 1 & 1 & 36 & Node1 & Node2 & Request & 0 & 0 & 300 & 0 & 0 & 0 & 0 & 164 & 230 & 336 & 270 & 0 & 0 & 0 & 0 & 0 & 0 & 0 & 273 & 427 & 0 & 0 \\
\hline & 1,1 & 1 & 9 & Node2 & Node5 & Request & 0 & 270 & 30 & 0 & 0 & 0 & 164 & 230 & 336 & 270 & 0 & 0 & 0 & 0 & 0 & 0 & 127 & 327 & 246 & 0 & 0 & 0 \\
\hline & 1,1 & 1 & 9 & Node5 & Node2 & Answer & 0[ & 226 & 74 & 0 & 0 & 0 & 164 & 230 & 336 & 270 & 0 & 0 & 0 & 0 & 0 & 0 & 127 & 327 & 246 & 0 & 0 & 0 \\
\hline & 1,2 & 1,1 & 9,9 & Node2 & Node5 & Request & 0 & 270 & 30 & 0 & 0 & 0 & 164 & 230 & 336 & 270 & 0 & 0 & 0 & 0 & 0 & 0 & 127 & 327 & 246 & 0 & 0 & 0 \\
\hline & 1,2 & 1,1 & 9,9 & Node5 & Node2 & Answer & 0 & 270 & 30 & 0 & 0 & 0 & 164 & 230 & 336 & 270 & 0 & 0 & 0 & 0 & 0 & 0 & 127 & 327 & 246 & 0 & 0 & 0 \\
\hline & 1 & 1 & 36 & Node2 & Node1 & Answer & 0 & 0 & 270 & 30 & 0 & 0 & 0 & 164 & 230 & 336 & 270 & 0 & 0 & 0 & 0 & 0 & 0 & 0 & 273 & 427 & 0 & 0 \\
\hline & 2 & 1,1 & 39,6 & Node1 & Node2 & Request & 0 & 0 & 300 & 0 & 0 & 0 & 0 & 164 & 230 & 336 & 270 & 0 & 0 & 0 & 0 & 0 & 0 & 0 & 273 & 427 & 0 & 0 \\
\hline & 2,1 & 1 & 9 & Node2 & Node5 & Request & 0 & 300 & 0 & 0 & 0 & 0 & 164 & 230 & 336 & 270 & 0 & 0 & 0 & 0 & 0 & 0 & 127 & 327 & 246 & 0 & 0 & 0 \\
\hline & 2,1 & 1 & 9 & Node5 & Node2 & Answer & 0 & 226 & 74 & 0 & 0 & 0 & 164 & 230 & 336 & 270 & 0 & 0 & 0 & 0 & 0 & 0 & 127 & 327 & 246 & 0 & 0 & 0 \\
\hline & 2,2 & 1,1 & 9,9 & Node2 & Node5 & Request & 0 & 300 & 0 & 0 & 0 & 0 & 164 & 230 & 336 & 270 & 0 & 0 & 0 & 0 & 0 & 0 & 127 & 327 & 246 & 0 & 0 & 0 \\
\hline & 2,2 & 1,1 & 9,9 & Node5 & Node2 & Answer & 0 & 300 & 0 & 0 & 0 & 0 & 164 & 230 & 336 & 270 & 0 & 0 & 0 & 0 & 0 & 0 & 127 & 327 & 246 & 0 & 0 & 0 \\
\hline & 2 & 1,1 & 39,6 & Node2 & Node1 & Answer & 0 & 0 & 300 & 0 & 0 & 0 & 0 & 164 & 230 & 336 & 270 & 0 & 0 & 0 & 0 & 0 & 0 & 0 & 273 & 427 & 0 & 0 \\
\hline
\end{tabular}

In scenario $S 1$, it is possible to see that, regarding to its idealistic perspective, every order is processed at the right time and in the depicts that, in the idealistic scenario S1, there is not improvement, which means that the Node1 is oriented to establish new 
proposals to push the supplier in order to get what it has been requested.

The behavior related to Node 2, as shown in the Figure 6, seems even more remarkable. This is due to the fact that Node2 has to deal with its customer and suppliers, hence the impact of a non-collaborative approach against a collaborative approach is clear. In addition, the profit level is higher when a collaborative approach is considered regarding to the fact that the $S P$ is increased and suppliers win more due to these incremented revenues from the customer. Moreover, the same effect can be observed from Figure 7, where the $S 3$ provides a higher profit level than $S 1$, where the idealistic scenario is considered. Thus, we can say that the $S P$ has a direct impact on the revenues and profit rated in the $n$-tier suppliers from the supply chain.

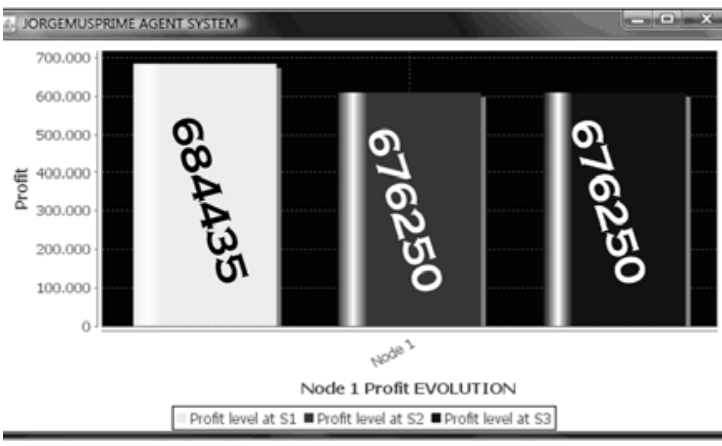

Figure 6. Profit evolution for the node N1.

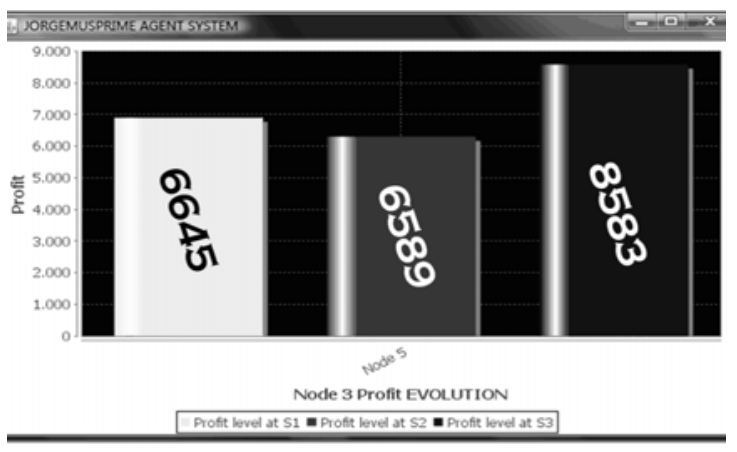

Figure 8. Profit evolution for the node N5.

Finally, from the supply chain point of view, the Figure 8 shows that the total profit value is higher for the $S 1$, which means that $S 1$ is ranked as the best scenario for the supply chain profit level evolution. On the other hand, the worst scenario is the noncollaborative. This can be explained because of the numerous order problems that are not fixed, which implies that the nodes must assume the cost of not fixing those problems. Finally, S3, as a realistic supply chain scenario, where supply chain nodes try to fix the problematic order, presents an economical solution and the supply chain profit is improved from the non-collaborative perspective.

\subsection{Contributions and limitations of the proposed model}

The ANEM proposal considers the wellknown agent technologies and their attributes. The main contribution (Table 2) of this work can be seen from two points of view. The first relates to the fact that the ANEM proposal is developed to cover dyadic and multi-level supply chain configurations in the information-sharing process context

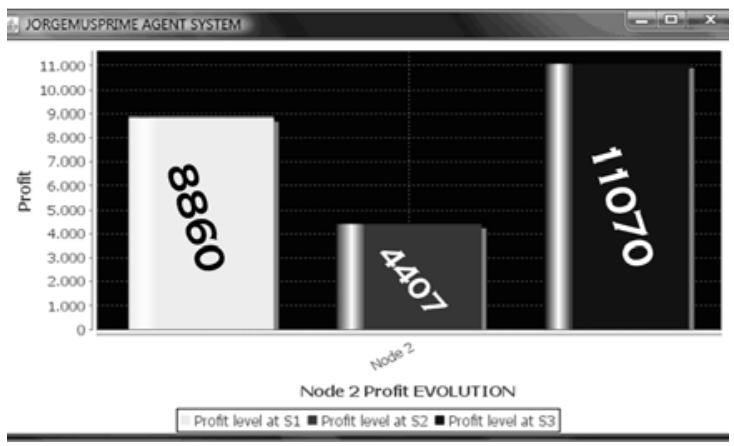

Figure 7. Profit evolution for the node N2.

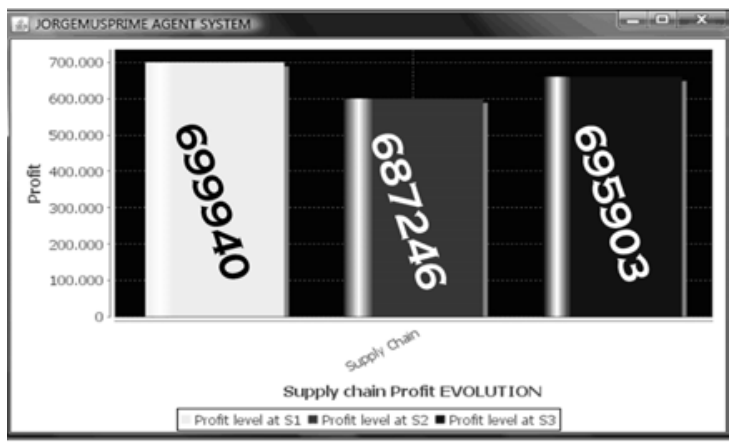

Figure 9. Profit evolution for the supply chain.

from a decentralized and collaborative approach. This implies that the novel approach of the ANEM proposal supports any kind of supply chain configuration. The second is taken from a negotiation point of view, ANEM considers the fact that each node collaborates and negotiates by 
considering its own interested goals, as well as the entire supply chain goals. This is supported by the price sharing level, which means that each node is open to receive new offers and to promote the negotiation process in the supply chain. Hence, Table 2 highlights the contributions offered by the agent-based model from the background and ANEM's contribution. is focused on: (1) the application of the proposed model to a real supply chain network; (2) the implementation of the mobility agent by scaling the platform prototype; and (3) the ANEM proposal will be combined with the work of [17] in order to support the collaborative planning under uncertainty.

Table 2. ANEM contributions. Qualitative analysis.

\begin{tabular}{|c|c|c|c|c|c|c|c|c|}
\hline \multirow{2}{*}{$\begin{array}{l}\text { Supply } \\
\text { chain }\end{array}$} & \multirow{2}{*}{$\begin{array}{c}\text { Collaborative } \\
\text { approach }\end{array}$} & \multicolumn{3}{|c|}{ Information sharing } & \multicolumn{3}{|c|}{ Negotiation parameters } & \multirow{2}{*}{$\begin{array}{c}\text { No } \\
\text { negotiation }\end{array}$} \\
\hline & & $\begin{array}{c}\text { Demand } \\
\text { Plan }\end{array}$ & $\begin{array}{c}\text { Capacity } \\
\text { level }\end{array}$ & $\begin{array}{c}\text { Inventory } \\
\text { level }\end{array}$ & $\begin{array}{c}\text { Supply chain } \\
\text { profit level }\end{array}$ & $\begin{array}{c}\text { Node profit } \\
\text { level }\end{array}$ & $\begin{array}{c}\text { Price } \\
\text { change }\end{array}$ & \\
\hline \multirow{2}{*}{ Dyadic } & Centralised & $\begin{array}{l}{[3],[7],[10],} \\
{[15],[24]}\end{array}$ & & [10] & [10], [15], [24] & & & [3], [7], [19] \\
\hline & Decentralised & [9], [21], ANEM & & [9], [21] & [9], [21], ANEM & [21], ANEM & ANEM & \\
\hline \multirow{2}{*}{ Multilevel } & Centralised & $\begin{array}{l}\text { [1], [2], [9], [14], } \\
{[23],[27]}\end{array}$ & [27] & [9], [27] & $\begin{array}{l}{[1],[9],[14],} \\
[23], 27]\end{array}$ & & [2] & [22] \\
\hline & Decentralised & $\begin{array}{l}\text { [11], [12], [14], } \\
{[18], \text { ANEM }}\end{array}$ & & [11] & $\begin{array}{l}\text { [11], [12], [14], } \\
{[18], \text { ANEM }}\end{array}$ & [12], ANEM & ANEM & \\
\hline
\end{tabular}

Finally, the main limitation of this proposal is that the ANEM proposal has been validated only with the illustrated numerical example. Therefore, the model should be contrasted longer with data from real-world supply chains, and the results should also be compared with other multiagent-based models.

\section{Conclusions}

A collaborative planning agent-based model and implementation to support the supply chain decentralized planning has been proposed. Decentralized collaborative planning aims the fact to identify collaborative and non-collaborative nodes in order to cope the planning mechanism of every supply chain node. The supply chain model based on the ANEM proposal has shown its usefulness to model complex configurations of supply chains. In addition, it has been shown that an improvement, thought as a collaborative negotiation process, in the supply chain profit level can be achieved. Finally, the main contributions of the ANEM proposal to support the collaborative processes modelling were shown. Hence, it has been able to appreciate the versatility of the proposed ANEM to cover different types of supply chains and to consider the perspectives of each node and the complete supply chain. Further research

\section{Acknowledgements}

This research has been funded by the REVOLUTION project (Ref. DPI201019977) funded by the Ministry of Science and Education of Spain, entitled "Production technology based on the feedback from decisions of production, transport and unload planning and the re-design of warehouses in the supply chain”.

\section{REFERENCES}

1. AKANLE, O. M., D. Z. ZHANG, Agent-based Model for Optimising Supply-chain Configurations, International Journal of Production Economics, Vol. 115, 2008, pp. 444-460.

2. ARAÚZO, J. A., J. PAJARES, A. LOPEZ-PAREDES, Simulating the Dynamic Scheduling of Project Portfolios, Simulation Modelling Practice and Theory, Vol. 18, 2010, pp. 1428-1441.

3. BA, S., R. KALAKOTA, A. B. WHINSTON, Using Client-brokerserver Architecture for Intranet Decision Support, Decision Support Systems, Vol. 19, 1997, pp. 171-192. 
4. BOUSQUETA, F., C. LE PAGE, Multiagent Simulations and Ecosystem Management: A Review, Ecological Modelling, Vol. 176, No. 3-4, 2004, pp. 313-332.

5. CHANG, J., B. CHOI, H. LEE, An Organizational Memory for Facilitating Knowledge: An Application to e-Business Architecture, Expert Systems with Applications, Vol. 26, 2004, pp. 203-215.

6. CHATFIELD, D. C., T. P. HARRISON, J. C. HAYYA, SCML: An Information Framework to Support Supply Chain Modelling, European Journal of Operational Research, Vol. 196, 2009, pp. 651-660.

7. CHEN, D., S. J. TURNER, W. CAI, M. XIONG, A Decoupled Federate Architecture for High Level Architecture-based Distributed Simulation, Journal of Parallel and Distributed Computing, Vol. 68, 2008, pp. 1487-1503.

8. CLARK, R., L. BONNEY, R. COLLINS, B. DENT, A. FEARNE, M. GOOCH, A. FELFEL, B. MCCALLUM, Assessing the Innovation Capabilities of an Atlantic Pork Value Chain, and Opportunities to Improve Performance in Relation to Consumer Demands, Internal Report of the The Value Chain Management, 2009, Canada. (http://www.vcmtools.ca/pdf/Atlantic\%2 0Canada\%20Pork\%20VCA\%20102610.p df, Accessed on December 20th, 2010)

9. DUDEK, G., H. STADTLER, Negotiation-based Collaborative Planning in Divergent Two-tier Supply Chains, International Journal of Production Research, Vol. 45(2), 2007, pp. 465-484.

10. FRAYRET, J. M., S. D'AMOURS, A. ROUSSEAU, S. HARVEY, J. GAUDREAULT, Agent-based Supplychain Planning in the Forest Products Industry, International Journal of Flexible Manufacturing Systems, Vol. 19, 2007, pp. 358-391.

11. FORGET, P., S. D'AMOURS, J. M. FRAYRET, J. GAUDREAULT, Study of the Performance of Multi-behaviour Agents for Supply Chain Planning, Computers in Industry, Vol. 60, 2009, pp. 698-708.

12. HERNÁNDEZ, J. E., M. M. E. ALEMANY, F. C. LARIO, R. POLER, SCAMM-CPA, A Supply Chain AgentBased Modelling Methodology That Supports a Collaborative Planning Process, Innovar, Vol. 19(34), 2009, pp. 99-120.

13. HERNÁNDEZ, J. E, R. POLER, J. MULA, An Interoperable Enterprise Architecture to Support Decentralized Collaborative Planning Processes in Supply Chain Networks, in: Enterprise Interoperability IV Springer (Ed.), 2010, pp. 213-224.

14. JUNG, H., F. F. CHEN, B. JEONG, Decentralized Supply Chain Planning Framework for Third Party Logistics Partnership, Computers \& Industrial Engineering, Vol. 55, 2008, pp. 348-364.

15. LU L., G. WANG, A Study On MultiAgent Supply Chain Framework Based On Network Economy, Computers \& Industrial Engineering, Vol. 54, 2008, pp. 288-300.

16. MANIAK R., C. MIDLER, Shifting From Co-Development To CoInnovation, International Journal of Automotive Technology and Management, Vol. 8, No. 4, 2008, pp. 449-468.

17. MULA J., R. POLER, Fuzzy Material Requirement Planning, In: C. Kahraman, M. Yavuz, Eds., Studies in Fuzziness and Soft Computing, Production Engineering and Management under Fuzziness, Springer (Ed.), 2010, Berlin, Heidelberg.

18. NAHM Y.E., H. ISHIKAWA, A Hybrid Multi-Agent System Architecture for Enterprise Integration Using Computer Networks, Robotics and Computer-Integrated Manufacturing, Vol. 21, 2005, pp. 217-234.

19. PAVÓN, J., J. GÓMEZ-SANZ, Agent Oriented Software Engineering with INGENIAS, Multi-Agent Systems and Applications III, in: Lecture Notes in 
Computer Science, Springer (Ed.), Vol. 2691, 2003, pp. 394-403.

20. POPA, V., L. CONSTANTINESCU, V. POPA, M. MOISE, C. ROTUNA, Management of Web Services Communities, WSC System, Studies in Informatics and Control, Vol. 19, No. 3, 2010, pp. 295-308.

21. SAAD, S., H. ZGAYA, S. HAMMADI, Novel Ontology Model for Communicating Heterogeneous Negotiation Mobile-Agent in a Transport Environment, Studies in Informatics and Control, Vol. 17(4), 2008, pp. 333-352.

22. SADEH, N. M, D. W. HILDUM, D. KJENSTADAND, A. TSENG, MASCOT: An Agent-Based Architecture for Coordinated MixedInitiative Supply Chain Planning and Scheduling, Third International Conference on Autonomous Agents (Agents '99), Workshop on Agent-Based Decision Support for Managing the Internet-Enabled Supply Chain, 1999, Seattle, US.

23. SHEN, W., Q. HAO, H. J. YOON, D. NORRIE, Applications of Agent-based Systems in Intelligent Manufacturing: An Updated Review, Advanced Engineering Informatics, Vol. 20, 2006, pp. 415-431.

24. SMIRNOV, A., N. SHILOV, A. KASHEVNIK, BTO Supply Chain Configuration via Agent-based Negotiation, International Journal of Manufacturing Technology and Management, Vol. 17(1/2), 2009, pp. 166-183.
25. SOOSAY, C. A., P. W. HYLAND, M. FERRER, Supply Chain Collaboration: Capabilities for Continuous Innovation, Supply Chain Management: An International Journal, Vol. 13(2), 2008, pp. 160-169.

26. ULIERU, M., D. NORRIE, R. KREMER, W. SHEN, A MultiResolution Collaborative Architecture for Web-Centric Global Manufacturing, Information Sciences, Vol. 127, 2000, pp. 3-21.

27. WANG, M., H. WANG, H. ZHENG, The Design of Agents Oriented Collaboration in SCM, The Third International Conference on Electronic Business (ICEB 2003), December 9-13, 2003, Singapore.

28. WADHWA, S., BIBHUSHAN, A. PRAKASH, Service Performance of Some Supply Chain Inventory Policies under Demand Impulses, Studies in Informatics and Control, Vol. 17(1), 2008, pp. 45-56.

29. ZUTSHI, A., Importance of Global Coinnovation Networks: A TCS Case Study, IET Working Papers Series No. WPS01/2009, 2009, pp. 1-23. 